\title{
Vulnerable Normality: Popular Neuroimaging and the Discursive Logic of the (Dis)able(d) Brain
}

\author{
By Kristofer Hansson \& Ellen Suneson
}

\begin{abstract}
The aim of this article is to analyse popular neuroimaging of (dis)able(d) brains as a cultural phenomenon, as well as to explore how there has been, during the last decades, a subtle but important change in the way "normal" brains are depicted in popular science. Popular neuroimaging is introduced and used as an empirical basis to analyse what Fiona Kumari Campbell sees as a critique against ableism. The empirical material consists of two British popular science documentaries (both produced by the BBC) on the topic of the brain: Human Brain (1983), and Brain Story (2004). The article argues that the position of normality and able-bodiedness has changed as the development of brain scanning techniques has emerged. In particular, there seems to have been a change in how the brain is visualized and talked about. New frameworks for understanding normality, disability and vulnerability have appeared. Furthermore, we claim that this shift needs to be studied from a theoretical perspective that analyses the discursive logic of the (dis)able(d) brain where an indistinctness transpires and creates a form of vulnerable normality.
\end{abstract}

Keywords: Ableism, brain, (dis)able(d), indistinctness, neuroscience, popular neuroimaging, popular science, vulnerable normality.

Hansson, Kristofer \& Ellen Suneson: "Vulnerable Normality: Popular Neuroimaging and the Discursive Logic of the (Dis)able(d) Brain", Culture Unbound, Volume 10, issue 1, 2018: 49-64. Published by Linköping University Electronic Press: http:// www.cultureunbound.ep.liu.se 


\section{Introduction}

"It's damage to the brain that reveals how the normal brain functions".

In the British popular science documentary series Brain Story from 2004, the female host, Professor of Pharmacology Susan Greenfield, uses neuroimagingpictures of the brain - to reveal hidden secrets about "the normal brain". Through different images of brain activity, the viewers are introduced to what is categorised as "disabled" brains. In this way the documentary visualises, by extension, what is categorised as normally functioning brains. Brain Story can be seen as a cultural expression of a visual turn that has occurred during the last decades within neuroscience, where images of brain activity have gained increasing influence (e.g. Dumit 2004, Dussauge 2008, Bengtsen \& Suneson 2017). As a part of this visual turn, neuroimaging has become a widespread phenomenon in various media such as fiction television series with a medical focus, popular science documentaries, journals and news reports. Through these media products, the general public are not only provided with visual depictions of brain activity but also with images of neurologists and neuroscientists looking at these visualisations. Furthermore, a common additional element is the deceptive narrative that medical experts are able to distinguish a "normal" brain from a disabled one based solely on the information they gain from looking at a brain scan. This plethora of visual imagery combined with specific narratives, ultimately has a considerable influence on what in this article will be called the discursive logic of the (dis)able(d) brain (cf. Davis 1995, Phillips 2001).

A recurrent discursive logic when brain scans are portrayed in popular media is that they are presented as a kind of photograph that visualises what is happening in the brain in relation to such characteristics as the human mind, personality and consciousness. This exemplifies how neuroscience has become a field of knowledge wherein it is widely imagined that the most complex and enigmatic questions of human characteristics can be answered. Theorists in the social and human sciences have pointed out how new brain-imaging technology is influencing our understanding of human behaviour (Dumit 2004, Dussauge 2008, Joyce 2008, Choudhury \& Slaby 2011, Rose \& Abi-Rached 2013, Liljefors $2012,2017)$. This new visual technology has emerged in the field of what we call popular neuroimaging (e.g. Beaulieu 2004, Dumit 2004, Vidal 2009, Hoel 2017). Here, the images do not only function as illustrations of scientific results but have also become central to the way neuroscientific knowledge is framed when presented to the general public (cf. Carusi \& Hoel 2014, Hoel \& Lindseth 2014). But it is also a field where discursive distinctions between the disabled brain and the "normal" brain are imagined (e.g. Jordan 2014, Adams \& Erevelles 2017). In 
this article, we bring together these cultural perspectives on neuroscience with a more critical disability perspective (e.g. Campbell 2008, Jordan 2014, Altermark 2018), by analysing popular science documentary series from the 1980s along with more recent series. In doing so, we want to add another layer to the discussion concerning cultural perspectives on neuroscience and popular neuroimaging. The aim is to analyse popular neuroimaging of the (dis)able(d) brain as a cultural phenomenon, as well as to explore how there has been, during the last decades, a subtle but important change in the way the "normal" brain is depicted in popular science.

\section{A Method for Studying Popular Neuroimaging}
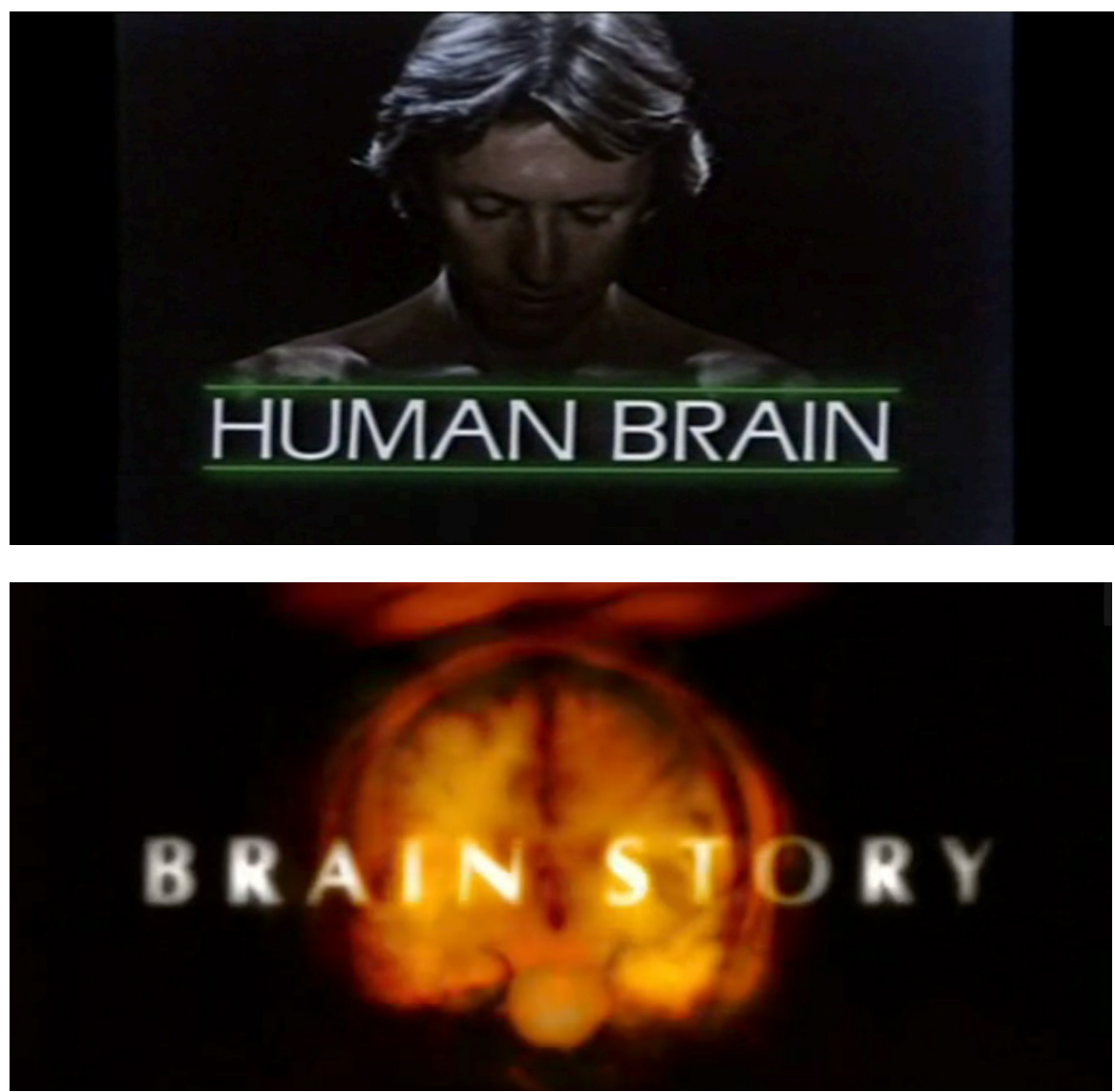

Figure 1 \& 2: The vignette to Human Brain (1983) and Brain Story (2004) produced by British Broadcasting Corporation in London. Looking at the background we can see that there are some differences'. In Human Brain the background is a silhouette of a head, but in Brain Story this has changed to a scanning image of a brain in an aesthetically appealing yellow colour. This latter figure is an example of popular neuroimaging and how scanning imagery is used to capture viewers' attention. 
Popular neuroimaging is nothing new. There is a long tradition of presenting visually complicated biomedical knowledge in popular form with the purpose of disseminating knowledge to the public (e.g. Hansson 2005). Even though brain scan imagery can be described as visual diagrams that should be interpreted as illustrations, popular media often presents these kinds of images as colourful photographs or snapshots that can be read in the same direct way as other photographic images (cf. Dumit 2004, Bengtsen \& Suneson 2017). This, however, is a simplification of the nature of brain scan imagery, which contributes to establishing an erroneous idea of scanning methods as a way of providing a visualisation of what is not otherwise available to the human eye. This can be compared with what Marita Sturken and Lisa Cartwright (2001) have noted about the camera commonly being framed in scientific research as an objective device that provides the capacity to see "truths" that are not available to the human eye. Images, we argue, have therefore become a form of actors that frame biomedical knowledge in specific ways (cf. Latour 2005, Carusi \& Hoel 2014). The use of the term popular neuroimaging highlights an emerging field where lay knowledge of the brain can be found almost everywhere in our daily life (Hansson \& Idvall 2017).

The empirical material of our study consists of two British popular science documentaries (both produced by the $\mathrm{BBC}$ ) on the topic of the brain: Human Brain (1983), and Brain Story (2004). Human Brain consists of seven episodes and Brain Story of six episodes. Even though there are two decades between them, the series are similarly constructed, with each episode focusing on a specific human trait or feeling. The viewers are presented to the subject by means of different cases; they are introduced to people who are challenged in their everyday lives due to the impairment of various functions in their brains. One example that describes this perspective is the sentence cited in the beginning of this article by Susan Greenfield, the host of Brain Story. Throughout the two documentary series, there is a tendency towards ableism; persons are characterized, firstly, by their disabilities, and second, in relation to non-disabled (e.g. Linton 1998, Thomas 2007, Campbell 2008). By applying a critical disability perspective we want to question these forms of cultural categorizations by following Fiona Kumari Campbell's thoughts on criticizing and even refusing this ableism:

Refusing Able(ness) necessitates a letting go of the strategy of using the sameness for equality arguments as the basis of liberal freedom. Instead of wasting time on the violence of normalization, theoretical and cultural producers could more meaningfully concentrate on developing a semiotics of exchange, an ontological decoder to recover and apprehend the lifeworlds of humans living peripherally. Ontological 
differences, be that on the basis of problematical signifiers of race, sex, sexuality and dis/ability, need to be unhinged from evaluative ranking and be re-cognised in their various nuances and complexities without being re-presented in fixed absolute terms. It is only then, in this release that we can find possibilities in ambiguity and resistance in marginality (Campbell 2008). ${ }^{1}$

Following Campbell's reasoning, we want to stress that critical methods and theories are needed to culturally understand how popular neuroimaging is used as a tool within the cultural processes of normalization. Or, to put it differently, how popular neuroimaging visualizes the (dis)able(d) brain and defines it in evaluative ranking terms.

Based on close readings, we have analysed selected narratives and visual depictions in our collected material. Visual depictions and narratives are in this analysis seen as part of the discursive logic of the (dis)able(d) brain (cf. Davis 1995, Phillips 2001), a theoretical perspective that is further developed below. For this article, we have used a small sample of documentaries in order to enable close readings where we have emphasized the deployment of specific visual and rhetorical narratives (Baldick 2015).

Examples from the series Human Brain and Brain Story analysed in this article substantiate many of the points that have been highlighted by researchers such as Joseph Dumit (2004), Nikolas Rose and Joelle M. Abi-Rached (2013). These thinkers discuss how the focus of neuroimaging has become increasingly influential in popular depictions of neuroscience over the last few decades, but also how pathology is the core of distinguishing disability from "normality". In this article we take this reasoning further by relating the more critical perspectives of neuroimaging to fields such as ethnology, visual culture and sociology, and adding perspectives from the field of disability studies. This combination of viewpoints involves focusing on the discursive logic of ableism, rather than on the disabilities themselves (e.g. McRuer 2006, Campbell 2008, Rydström 2012, Jordan 2014, Altermark 2018). Central to our thesis is the notion that the logic of ability is a cultural process, and that distinctions between inclusion and exclusion become blurred in the context of popular neuroimaging (cf. Jordan 2014). In the following section we will look at an example of popular neuroimaging and how the brain is framed and visualized in one of the episodes of the documentary series Brain Story. 


\section{The Brain as a Story in a Popular Science Documentary}

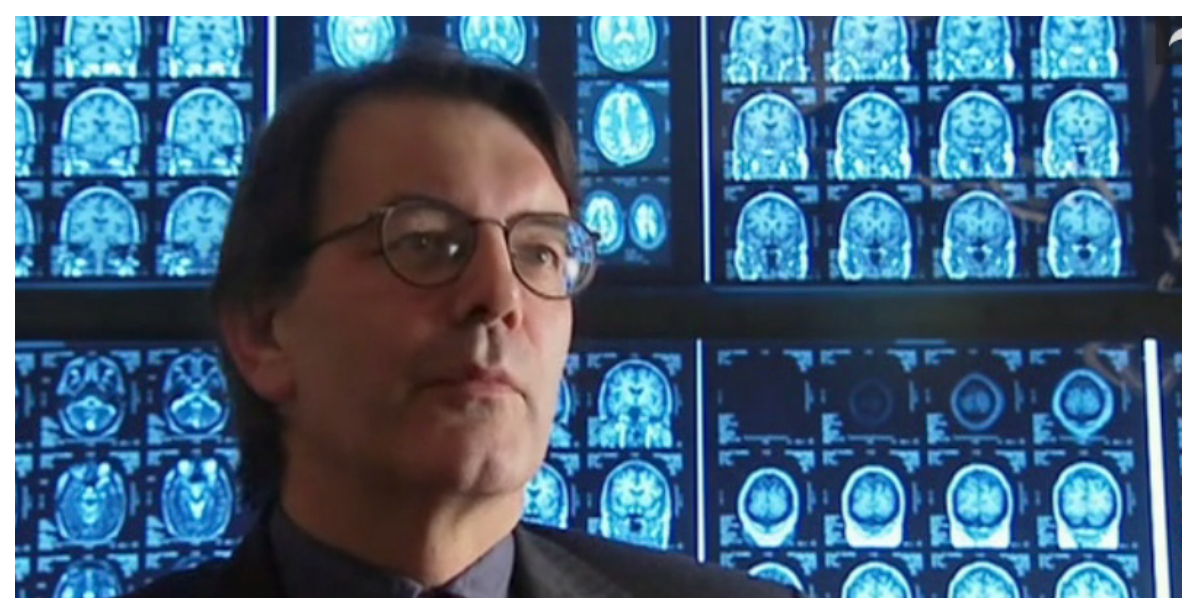

Figure 3: A screenshot from Brain Story (2004, BBC) and the first episode "All in the Mind", where the neurologist John Hodges is interviewed in front of a large amount of brain scanning images. This background is supposed to give the viewers a contextualisation of the milieu Hodges works in.

In the first episode of Brain Story (2004), the viewers are introduced to Denis Sines - a Vietnam veteran who was traumatised during the war. Sines describes during an interview how his PTSD (Post Traumatic Stress Disorder) prevents him from performing daily chores and maintaining his close relationships. Furthermore, Sines explains how his disorder makes him suicidal at times. In one scene Sines is slid into a MRI (Magnetic Resonance Imaging) ${ }^{2}$ scanner while the host of the documentary, Professor Greenfield, explains that neuroscientists are studying Sines' brain while exposing him to pictures and sounds designed to frighten him. Greenfield goes on to describe how scientists, by studying the brain circuits involved in Sines' fear response, want to examine how his brain has changed due to his traumatic experiences. The documentary is in this way connected with the growing discussion about neuroplasticity (Doidge 2007). As opposed to previous assertions that the brain does not change after infancy, neuroplasticity implies the understanding of the brain as "plastic". From the point of view of neuroplasticity, then, the brain constantly changes as a result of one's experiences (cf. Rose \& Abi-Rached 2013). As we will argue, this has implications for making discursive distinctions between "deviant" and "normal" brains.

In the next scene in the sequence about Sines, we are introduced to neurologist John Hodges who is standing in a hospital milieu in front of a variety of MRI scans (Figure 3). Hodges points with a pen at one of the images while explaining that the fear Sines experienced during the war has changed the very structure of his brain. 


\section{Culture Unbound}

Journal of Current Cultural Research

We did an MRI scan on Denis and this is his hippocampus here, this grey area there, and it's visibly... I can just look at the scan and tell you that it's smaller in volume compared to a normal individual where the hippocampus is much larger.

As Hodges mentions the "normal individual", he points to another of the MRI scans on display behind him and uses his pen to show how the hippocampus of that particular brain image is larger in size. Who the brain he defines as "normal" belongs to and what criteria he uses to determine it as normal is never explained.

As mentioned, previous research has pointed out how this manner of presenting brain scans as a kind of photographic snapshot provides the general public with an inaccurate impression of the capacity of scanning techniques (cf. Dumit 2004, Abi-Rached \& Rose 2010). While the framing of brain scanning techniques as a way of "seeing" an individual's feelings, experiences or characteristics may be an intriguing narrative within popular media, it also has problematic consequences for the discursive logic of the (dis)able(d) brain. In Brain Story, Sines' brain is visualized and narratively defined as different. In this way, the brain becomes an object of ontological difference, placed in an evaluative ranking of other (dis) able(d) brains. This is an example of the strategy Fiona Kumari Campbell (2008) calls sameness, and that leads us to a form of "violence of normalization" where popular neuroimaging claims to enable a distinction between different "kinds of brains" (Dumit 2004).

\section{Brain Images and the Human Brain in the 1980s}

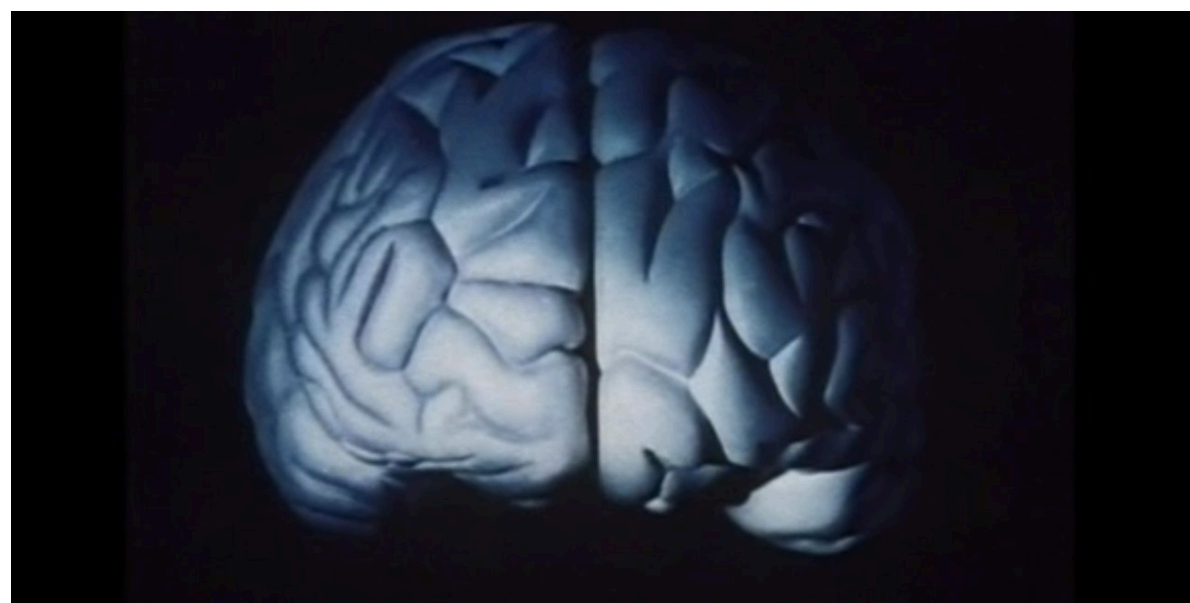

Figure 4: This is a common illustration of the brain in the popular science documentary series Human Brain (1983, BBC). Compared to representations of scanning techniques in the more recent documentary series Brain Story, this illustration does not have the same scientific authority, since it cannot be used by medical expertise to reveal "secrets" within the visualisation. 
Brain scanning images mainly started to appear in popular media during the 1980s (Dumit 2004). From the very beginning these images were used to visualise different "kinds of brains", such as "normal", "schizophrenic", "depressed" or "psychopathic". This mode of equating the visual appearance of the human brain with different personality types has since grown steadily stronger. ${ }^{3}$ In contrast, the popular science documentary series Human Brain (1983) visualises the brain by using anatomical illustrations of the brain as an organ (Figure 4). Here, there are no visual depictions of brain activity nor are there any images of neurologists and neuroscientists looking at these visualisations. For this reason, the series' verbal accounts seem to become more central than in Brain Story (2004). In the following examples we will discuss how these verbal accounts are used as a presentation of a certain perspective about the brain's fear responses.

The sixth episode Human Brain deals with the phenomenon of fear. In the first feature of the episode the viewers are introduced to Peter-a man in his twenties who is going to make a solo appearance in connection with a concert with his orchestra. The documentary's voiceover explains that Peter's anxiety before concerts often ruins his performance, but that Peter can resolve the situation by taking drugs that reduce his stress symptoms. Later in the sequence, an experiment is depicted where all of the members of the orchestra are given drugs before a concert. Without knowing in advance what kind of pills they received, half of the members were given a sedative drug while the other half were given ineffective sugar pills. The objective of the experiment was to investigate if sedatives really work and whether the sugar pills had any placebo effects on the members of the orchestra. Despite the fact that none of the members knew what kind of pills they received, the surveys carried out in connection with the experiment showed that the members who were given the real sedative drug felt less stress than those who received sugar pills. However, the episode does not present an exclusively favourable account of this use of medicine. In order to nuance the abilities of sedative drugs, a later sequence in the episode deals with the fear of spiders. In this sequence, we are introduced to two people who suffer from fear of spiders (arachnophobia) - the well-known journalist Bernard Levin and a young woman named Beverly. The sequence features therapy sessions where Beverly is confronted with spiders in order to overcome her fear. This feature seems to serve as a follow-up to the section with Peter, and the documentary's voiceover explains that therapy cannot be replaced by sedative drugs in the long run. The programme underscores that sedative drugs such as Valium may suppress anxiety for a short period of time. However, in order to alter the chemistry of the brain permanently so that the effect persists, one also needs psychotherapy.

The documentary has an outspoken objective of using different examples of brains in order to illustrate how the "normal" brain functions. In this way it 
shares many common narrative elements with Brain Story (2004). However, what is interesting is who these brains belong to: whose brains are used in the various examples and how are these persons portrayed? Brain Story almost exclusively uses brains that belong to people that are defined as "disabled" in order to visualize neurological functions, while Human Brain uses a greater variety of examples in its depictions of brain activity. Looking at this disparity between the two series, it therefore seems that the distinctions between able brains and disabled brains have changed (cf. Jordan 2014). It's as if the discursive logic of the (dis)able(d) brain intertwines with normalization processes in new ways.

\section{Vulnerable Normality in Popular Neuroimaging}

Brain Story (2004) almost exclusively equates brain damage with disability. The portrayal of the brain in this documentary series exemplifies a shift in popular neuroscience where the brain is predominantly illustrated as either "deviant" or "normal". We argue here that this is not as prominent in older examples of popular neuroscience such as the documentary series Human Brain (1983). This shift over time may illustrate a change in the discursive logic of the (dis)able(d) brain, something that can be discussed with a starting point in the concept of plasticity. Plasticity within neuroscience is intertwined with the focus on brain scanning techniques; within both fields, emphasis has shifted from identifying various parts and structures of the brain to the study of brain activity. In this way, the contemporary visual field of brain imaging is strongly interlinked with the idea of plasticity. Plasticity has also brought along an idea that individuals should take care of their malleable brain, to keep it vital (cf. Alftberg \& Hansson 2012). In this way, the discursive logic of the (dis)able(d) brain intertwines with what can be called scientific authority. ${ }^{4}$ So, we argue that this distinction between the care of the brain and scientific authority is central if we want to understand popular neuroscience today, but we need to develop and problematize this theoretically as an indistinctness (Jordan 2014, e.g. Agamben 1998, Žižek 2010) between the able brain and the (dis)able(d) brain.

Throughout nearly all of the sequences in the episodes of Brain Story, the brain is used to illustrate people that are categorized as disabled. In the case of Sines, he is introduced to the viewer through a description of how his PTSD (a disorder that is later in the episode explained as physical brain damage) makes it hard for him to participate in everyday life. He shuts out his family emotionally, which erodes his relationship with them, he cannot work, and he suffers from depression. The episode also illustrates Sines' impairments through visual and audio effects. While Sines himself talks about his experience of being unable to perform daily chores, his description is further reinforced through a visual example depicting 
a chaotic urban environment. Here, rapid visual elements appear suddenly in an unpleasant way and horrible sounds from a war zone are applied as an audio track in order to illustrate Sines' experience of fear in public environments. The viewers are thus made to experience by proxy how Sines' brain damage hinders him from functioning properly in situations such as at work, in family life and in public life. There is no specific situation or place that illustrates when or how Sines experiences that his disability limits his life. Instead, his disability is rendered as comprehensive. It seemingly affects him all the time, in everything he does.

A matter that particularly captured our attention when conducting close readings of the documentaries, was that as brain scanning imagery has consolidated the assumption of neuroscience's ability to visualise personality types, a notion of the brain's vulnerability has received growing attention. The discursive logic of able-bodiedness does not try to eliminate the disabled body. Instead, as is evident in Brain Story, impairment and disability is often presented as a permanent threat towards the "normal" brain (Jordan 2014). Psychologist Thomas Jordan discusses this logic based on e.g. Michel Foucault and Giorgio Agamben (1979 \& 1990):

What Foucault's work seems to intuit but never makes explicit is that the discourse of able-bodiedness, far from trying to eliminate the disabled body, requires it as a permanent threat and an imminent possibility for its very operation. In other words, disability and able-bodiedness name two sides of the same biopolitical coin (Jordan 2014: 31).

Based on the theories of Agamben, Jordan argues that political subjects are constructed through the relationship between the rule and the exception. ${ }^{5}$ The latter is necessary to enforce the former. To understand the meaning of being included, of being a citizen or of belonging to a nation, excluded subjectsnon-citizens, persons that do not belong to the specific nation-state-are needed (Agamben 1998). Agamben argues that the moment we exclude something, we will include it in the form of the exception that proves the rule.

According to Agamben, we are all exposed to the vulnerability of potentially being relegated to this excluded position (Agamben 1998). So, to fight merely for the inclusion of the excluded is-according to Jordan's argument, based on Agamben-to misunderstand the vulnerable position all human beings find themselves in (Jordan 2014, cf. Butler 2004). All humans face the threat of not passing as "normal", either by congenital conditions or by contextual definitions. This ultimately means that one's status as a political subject is constantly under the threat of being downgraded or impeded. ${ }^{6}$ Similarly to Jordan's description of how the disabled or excluded body is needed to define the functional or included body, the excluded body is used in Brain Story to define ableism. When the documentary 
is describing function by non-function, this is used to make a distinction between the "normal" brain and the "deviant" brain. What we wish to highlight here is that this distinction becomes a reminder of the vulnerability of the human brain.

But there is also a parallel narrative in Brain Story that counteracts this reading: the positioning of disability and normality as binary opposites. Many of the narratives tell us how the disability of various people restrains them and affects their lives negatively. We learn how the people presented in the shows cannot work, perform simple tasks or behave in a socially acceptable mannersomething a person who is characterized as "normal" is able to. Here, the disabled body becomes an object of fear. What defines a normal person is never specified. Therefore, cultural assumptions play a vital role in the mediation of scientific images between e.g. the scientific community, popular magazines and television documentaries. The framing of neuroimagery affects public understanding of neuroscience, and ultimately informs discourses of vulnerability.

This establishes the disabled body as the excluded object in relation to the included able-bodied subject. The threat of exclusion-constantly present but never defined-is central in attracting us to, and putting our faith in, modern neuromedicine (cf. Brown 2003). In the last episode of Brain Story, the host of the documentary reveals this hope in relation to brain imaging techniques when the diagnosis for depression is discussed:

This new century will bring great advances in our understanding of the brain. As imaging techniques improve, we'll be able to monitor the brain's activity in all its complexity as it flits from thought to thought $(\ldots)$ and as we gain insights into the brain processes that are necessary for happiness, then we may have powerful new ways to treat depression.

Here, the individual is described as an autonomous and independent entity. Disability and depression are something that happens in you and not something that happens to you in particular situations. Instead of seeing depression as a symptom of something being wrong with your relationship with the surrounding environment, the cause is to be found (and remedied) in the brain. As is clear from the above quote, this rhetoric is closely intertwined with narratives about the progress of medicine-if neuro research continues to evolve, it may in the future fix your brain if it is damaged or not functioning optimally. Returning to our previous reasoning, the scientific authority of modern neuromedicine can theoretically be seen, not only as a distinction between the abled brain and the 
disabled brain, but also as an indistinctness (Jordan 2014, e.g. Agamben 1998, Žižek 2010) where the (dis)able(d) brain is a potential part of all people.

\section{Concluding Remarks: What about the (Dis)able(d) Brain?}

Although both Human Brain (1983) and Brain Story (2004) contain similarities, there are important differences between them. These differences lie in the description of the position of normality and able-bodiedness and are strongly linked to popular neuroimaging and the discourses of social or medical impairment that are formed in parallel with the development of brain scanning techniques. There seems to have been a change in how neurological processes are visualized and talked about (cf. Davis 1995, Phillips 2001). As neuroscience evolves and moves towards a more detailed division of brains into different categories, new frameworks for understanding normality, disability and vulnerability have appeared. The recent shift within neuroscience towards ideas of neuroplasticity and the development of visualization technologies, has hampered the general public's access to the processes that lead to new definitions of normality. The criteria that determine whether someone passes as "able-brained" are therefore not necessarily visible or noticeable to lay people (cf. Beck 1992). Instead, it is the scientists and the doctors who possess the knowledge and ability to decipher brain activity (cf. Wynne 1996, Pellizzoni 1999 \& 2001).

Having studied British popular science documentaries, we argue that there seems to be a shift in popular media's visualisations of the "normal" brain over the past few decades. Furthermore, we claim that this shift needs to be studied from a theoretical perspective that analyses the discursive logic of the (dis)able(d) brain where an indistinctness transpires and creates a form of vulnerable normality. During recent decades, the circulation of scanning images, showing cross sections of brains, has increased drastically. In popular media products, these images are commonly presented as visual evidence-or scientific authority-that makes it possible to distinguish the "normal" from the "deviant", injured or disabled. But the way visual technology within neuroscience, such as MRI, is depicted within popular neuroimaging ultimately also presents a form of indistinctness. From this perspective it is not only an accident or illness that threaten the status of an able-bodied subject. Instead, as Jordan (2014) also points out, a new threat of vulnerability is formulated: anyone can be defined as "abnormal", "deviant" or disabled at any time. 


\section{Notes}

${ }^{1}$ Here, Fiona Kumari Campbell's reasoning is inspired by the theories of e.g. bell hooks (1990) and Simone de Beauvoir (1948).

${ }^{2}$ In a previous chapter, Hansson has described the MRI process as follows: "to produce images from a MRI scanner, the machine must for a brief space of time make the hydrogen atoms of the body send out faint radio waves. The waves are detected by the machine and after computer processing, a section image of, for example, the brain is produced. The image is thus not just created in the traditional way by a camera registering objects in front of it; the scanner is itself highly involved in producing the image by means of waves and computer processing. Hence, the knowledge does not only exist in the picture, the image depends on the procedure of the machine processing in the computer and on how its information is interpreted by the observer" (Hansson 2017: 22).

${ }^{3}$ Medical science's division of human beings into categories or personality types based on visual differences is nothing new (cf. Foucault 2003). The social and human sciences have pointed out the close connections between brain scanning techniques and the phrenology of the 19th century (cf. Cooter 1984). Phrenology assumed that it is possible to deduce personality and character by the shape of the human head. Contemporary research based on brain scanning techniques aim to identify how functional regions in the brain affect human characteristics such as morale, anxiety, social skills, sexuality, intelligence, learning, language, memory and perceptioncharacteristics similar to those that were studied in phrenology (Dumit 2004).

${ }^{4}$ This is a reliance strongly rooted in Foucault's discussions about biopolitics, a concept that lets us see how the discursive logic of the (dis)able(d) brain intertwines with scientific authority (Foucault 1990, e.g. Agamben 1998, Rose 2007, Gottweis 2008, Žižek 2010, Schimtz \& Höppner 2014).

${ }^{5}$ Throughout our analysis we have left Agamben's discussion about sovereign power and bare life from a biopolitical perspective aside (Agamben 1998), and instead focused on how disability and able-bodiedness are interwoven in popular neuroimaging.

${ }^{6}$ Here we are interested in the discursive logic of disability and not the disabilities themselves or the experiences of disabilities in the lifeworld (e.g. McRuer 2006, Rydström 2012).

\section{Acknowledgements}

Thanks to Åsa Alftberg, Malmö University, Peter Bengtsen, Lund University, and the two anonymous reviewers for thorough and constructive comments. The research is supported by BAGADILICO_Basal Ganglia Disorders Linnaeus Consortium - at Lund University. 


\section{Culture Unbound}

Journal of Current Cultural Research

Kristofer Hansson is associate professor of Ethnology and researcher at the Department of Arts and Cultural Sciences, Lund University. He did his PhD studies at Vardalinstitutet-The Swedish Institute for Health Sciences. His research focus is cultural analysis of medical praxis in health care and biomedical research. In recent years much of his research is related to citizen participation in new biomedical technologies. Email: kristofer.hansson@kultur.lu.se

Ellen Suneson is a $\mathrm{PhD}$ candidate in Art History and Visual Studies at Lund University. Her research interests concern queer feminism, performativity and art historiography. Suneson has been part of various projects concerning art and neuroscience-with a focus both on the intersection between popular culture and neuroscience and on developing methods for art therapy aimed at Parkinson's patients. Email: ellen.suneson@kultur.lu.se

\section{References}

Abi-Rached, Joelle M. \& Rose, Nikolas (2010): 'The Birth of the Neuromolecular Gaze', History of the Human Sciences, 23:1, 11-36.

Adams, DL \& Erevelles, Nirmala (2017): 'Unexpected Spaces of Confinement: Aversive Technologies, Intellectual Disability, and "Bare Life", Punishment \& Society, 19:3, 348-365.

Agamben, Giorgio (1998). Homo Sacer: Sovereign Power and Bare Life, Stanford: Stanford University Press.

Alftberg, Åsa \& Hansson, Kristofer (2012): 'Self-Care Translated into Practice', Culture Unbound: Journal of Current Cultural Research, 4, 415-424.

Altermark, Niklas (2018): Citizenship Inclusion and Intellectual Disability: Biopolitics Post-institutionalisation, Abingdon: Routledge.

Baldick, Chris (2015): The Oxford Dictionary of Literary Terms. $4^{\text {th }}$ ed., Oxford: Oxford University Press.

Beauvoir, Simone de (1976 /1948): The Ethics of Ambiguity, New York: Kensington Publishing Corp.

Beaulieu, Anne (2004): 'From Brainbank to Database: The Informational Turn in the Study of the Brain', Studies in History and Philosophy of Science Part C: Studies in History and Philosophy of Biological and Biomedical Sciences, 35:2, 367-390.

Beck, Ulrich (1992): Risk Society: Towards a New Modernity, London: Sage.

Bengtsen, Peter \& Suneson, Ellen (2017): 'Pathological Creativity: How Popular Media Connect Neurological Disease and Creative Practices', Kristofer Hansson \& Markus Idvall (eds): Interpreting the Brain in Society. Cultural Reflections on Neuroscientific Practices, Lund: Arkiv Förlag, 29-47.

Brown, Nik (2003): 'Hope Against Hype: Accountability in Biopasts, Presents and Futures', Social Studies of Science, 16:2, 3-21.

Butler, Judith (2004): Precarious Life: The Powers of Mourning and Violence, London: Verso.

Campbell, Fiona Kumari (2008): 'Refusing Able(ness): A Preliminary Conversation About Ableism', M/C Journal, 11:3, http://journal.media-culture.org.au/index.php/ mcjournal/article/viewArticle/46 (accessed April 05, 2018).

Carusi, Annamaria \& Aud Sissel Hoel (2014): 'Toward a New Ontology of Scientific Vision', Catelijne Coopmans, Janet Vertesi, Michael E. Lynch \& Lynch Woolgar (eds): Representation in Scientific Practice Revisited, Cambridge: MIT Press, 201-221.

Choudhury, Suparna \& Slaby, Jan (2011): Critical Neuroscience: A Handbook of the Social and Cultural Contexts of Neuroscience, Chichester, West Sussex: Wiley-Blackwell. 


\section{Culture Unbound}

Journal of Current Cultural Research

Cooter, Roger (1984): The Cultural Meaning of Popular Science: Phrenology and the Organization of Consent in Nineteenth-Century Britain, Cambridge: Cambridge University Press.

Davis, Lennard J. (1995): Enforcing Normalcy: Disability, Deafness, and the Body, New York: Verso.

Doidge, Norman (2007): The Brain that Changes Itself: Stories of Personal Triumph from the Frontiers of Brain Science, New York: Viking.

Dumit, Joseph (2004): Picturing Personhood: Brain Scans and Diagnostic Identity, Princeton, N.J.: Princeton University Press.

Dussauge, Isabelle (2008): Technomedical Visions: Magnetic Resonance Imaging in 1980s Sweden, Stockholm: Kungliga Tekniska högskolan.

Foucault, Michel (1979/1975): Discipline and Punish, New York: Vintage.

Foucault, Michel (1990/1976): The history of sexuality. Vol. 1, The will to knowledge, Harmondsworth: Penguin.

Foucault, Michel (2003/1973): The Birth of the Clinic: An Archaeology of Medical Perception, London: Routledge.

Gottweis, Herbert (2008): 'Participation and the New Governance of Life', BioSocieties, 3:3, 265-286.

Hansson, Kristofer (2005): 'Biopop: Biovetenskapens popularisering i medierna' [Biopop: The Popularisation of Biomedicine in the Medias], ETN: Etnologisk skriftserie, 1:1, 107-117.

Hansson, Kristofer (2017): 'A Different Kind of Engagement: P.C. Jersild's Novel A Living Soul', Kristofer Hansson \& Markus Idvall (eds): Interpreting the brain in society. Cultural reflections on neuroscientific practices, Lund: Arkiv Förlag, $17-28$.

Hansson, Kristofer \& Idvall, Markus (2017): 'Introduction: Interpreting the Brain in Society', Kristofer Hansson \& Markus Idvall (eds): Interpreting the Brain in Society: Cultural Reflections on Neuroscientific Practices, Lund: Arkiv Förlag, $11-15$

Hoel, Aud Sissel \& Lindseth, Frank (2014): 'Differential Interventions: Images as Operative Tools', The new Everyday: A MediaCommons Project, 'The Operative Image' Cluster, curated by Ingrid Hoelzl, http://mediacommons.futureofthebook. org/tne/pieces/differential-interventions-images-operative-tools-2 (accessed April 05, 2018).

Hoel, Aud Sissel (2017): 'Styles of Seeing and Knowing in the Neurosciences', Kristofer Hansson \& Markus Idvall (eds): Interpreting the Brain in Society: Cultural Reflections on Neuroscientific Practices, Lund: Arkiv Förlag, 157-163.

hooks, bell (1990): Yearning: Race, Gender, and Cultural Politics, Boston, MA: South End Press.

Jordan, Thomas (2014): 'Disability, Able-Bodiedness, and the Biopolitical Imagination', Review of Disability Studies: An International Journal, 9:1, 26-38.

Joyce, Kelly A. (2008): Magnetic Appeal: MRI and the Myth of Transparency, Ithaca \& London: Cornell University Press.

Latour, Bruno (2005): Reassembling the Social: An Introduction to Actor-Network-Theory, Oxford: Oxford University Press.

Liljefors, Max (2012): 'Neuronal Fantasies: Reading Neuroscience with Schreber', Max Liljefors, Susanne Lundin \& Andrea Wiszmeg (eds): The Atomized Body: The Cultural Life of Stem Cells, Genes and Neurons, Lund: Nordic Academic Press, 143-169.

Liljefors, Max (2017): ' 'Biospace': Metaphors of Space in Microbiological Images', Kristofer Hansson \& Markus Idvall (eds): Interpreting the Brain in Society. Cultural Reflections on Neuroscientific Practices, Lund: Arkiv Förlag, 49-71.

Linton, Simi (1998): Claiming Disability: Knowledge and Identity, New York: New York University Press. 


\section{Culture Unbound}

Journal of Current Cultural Research

McRuer, Robert (2006): Crip Theory: Cultural Signs of Queerness and Disability, New York: New York University Press.

Pellizzoni, Luigi (1999): 'Reflexive Modernisation and Beyond Knowledge and Value in the Politics of Environment and Technology', Theory, Culture and Society, 16:4, 99-125.

Pellizzoni, Luigi (2001): 'The Myth of the Best Argument: Power, Deliberation and Reason', British Journal of Sociology, 52:1, 59-86.

Phillips, Cassandra (2001): 'Re-imagining the (Dis)Abled Body', Journal of Medical Humanities, 22:3, 195-208.

Rose, Nikolas (2007): The Politics of Life Itself: Biomedicine, Power, and Subjectivity in the Twenty-first Century, Princeton: Princeton University Press.

Rose, Nikolas \& Abi-Rached, Joelle M. (2013): Neuro: The New Brain Sciences and the Management of the Mind, Princeton: Princeton University Press.

Rydström, Jens (2012): 'Introduction: Crip Theory in Scandinavia', Lambda Nordica, $17: 1-2,9-20$.

Schimtz, Sigrid \& Grit Höppner (2014): 'Catching the Brain Today: From Neurofeminism to Gendered Neurocultures', Sigrid Schmitz \& Gritt Höppner (eds): Gendered Neurocultures: Feminist and Queer Perspectives on Current Brain Discourses, Vienna: Zaglossus, 9-37.

Sturken, Marita \& Cartwright, Lisa (2001): Practices of Looking: An Introduction to Visual Culture, Oxford: Oxford University Press.

Thomas, Carol (2007): Sociologies of Disability and Illness: Contested Ideas in Disability Studies and Medical Sociology, Basingstoke: Palgrave Macmillan.

Vidal, Fernando (2009): 'Brainhood, Anthropological Figure of Modernity', History of the Human Sciences, 22:1, 5-36.

Žižek, Slavoj (2010): Living in the End Times, London: Verso.

Wynne, Brian (1996/1992): 'Misunderstood Misunderstanding: Social Identities and Public Uptake of Science', Alan Irwin \& Brian Wynne (eds): Misunderstanding Science? The Public Reconstruction of Science and Technology, Cambridge: Cambridge University Press, 19-46. 